\title{
MEMÓRIA E (RE)CRIAÇÃO NA FORMAÇÃO DE PROFESSORES: TRILHANDO CAMINHOS*
}

\author{
Simone Cristiane Silveira Cintra ${ }^{* *}$ \\ Ana AngÉlica Albano ${ }^{* *+}$
}

\begin{abstract}
RESUMO: Este trabalho apresenta resultados parciais de uma pesquisa sobre as possibilidades formativas estabelecidas na relação entre memória, criação e formação docente. O texto traz reflexões sobre aspectos de uma prática de formação realizada com alunas do curso de Pedagogia da Universidade Estadual de Campinas. Objetivamos, com esta reflexão, estabelecer relações entre os processos de rememoração e de criação de narrativas cênicas vivenciados pelas alunas, na perspectiva de que essas relações venham a contribuir para a pesquisa e as práticas de formação docente. Constituem os referenciais teóricos deste trabalho estudos sobre a pesquisa (auto)biográfica e aportes da Psicologia Analítica de Carl Gustav Jung. Resulta dessa análise a identificação dos processos de criação como espaços privilegiados para a produção e elaboração de símbolos, potencializando a ordenação do vivido por meio do rememorar, do encenar histórias de vida e do registro das experiências de formação com palavras e imagens.
\end{abstract}

Palavras-chave: Memória. Símbolo. Formação de professor. Psicologia Analítica.

* Pesquisa realizada com apoio da Fundação de Amparo à Pesquisa do Estado de São Paulo (FAPESP).

** Doutoranda no Programa de Pós-Graduação em Educação da Faculdade de Educação da Universidade Estadual de Campinas (UnICAMP).E-mail: sccintra@hotmail.com

*** Doutora em Psicologia Social e professora da Faculdade de Educação da UNICAMP. E-mail: nanalbano@uol.com.br 
Memória e (re)criação na formação de professores: trilhando caminhos

MEMORY AND (RE)CREATION IN TEACHER EDUCATION: TREADING PATHS

ABSTRACT: This work presents partial results of a research on the training possibilities established by the relations among memory, creation and teacher education. It brings reflections about the training practice developed with students of the Graduation in Pedagogy of the State University of Campinas. Those reflections intend to establish relations between the processes of remembering and of creating theatrical narratives experienced by the students, expecting that those relations can contribute to the research and practices of teacher education. The theoretical framework is basically constituted by the studies of self-biographic approach and concepts of the Analytical Psychology of Carl Gustav Jung. This analysis results in the identification of creation processes as a privileged space to produce and draw up symbols allowing to ordinate has been experienced through the acts of remembering, staging life stories, writing and drawing from the experiences lived.

Key words: Memory. Symbol. Teacher education. Analytical Psychology.

\section{Introdução}

D

entre as diferentes abordagens metodológicas adotadas pela área de formação de professores, destacam-se hoje as metodologias que tomam a vida do professor como importante elemento reflexivo tanto para as práticas de formação docente, como para a pesquisa acerca dessa formação.

A pesquisa de doutorado abordada neste texto está pautada nessa perspectiva, tratando-se de uma investigação-formação que engloba a realização concomitante de práticas formativas e a investigação das mesmas.

Para este trabalho elegemos alguns aspectos de uma prática de formação, realizada durante o segundo semestre de 2007, com alunas do curso de Pedagogia da Universidade Estadual de Campinas (UNICAMP). Essa prática ocorreu em uma das disciplinas que integra a grade curricular do curso, ministrada pela primeira autora deste texto, que desempenhava a função de estagiária do Programa de Estágio Docente da Pós-Graduação em Educação da UNICAMP. 
As atividades foram sistematizadas de modo a proporcionar às alunas a vivência de jogos teatrais, de processos de reconstrução de memórias e a criação de narrativas cênicas a partir de suas lembranças de escola, de infância e de adolescência.

É nosso objetivo, com esta reflexão, estabelecer relações entre os processos de rememoração e de criação de narrativas cênicas vivenciados pelas alunas do curso de Pedagogia, na perspectiva de que essas relações venham a contribuir para a pesquisa e as práticas de formação docente.

Constituem os referenciais teóricos deste trabalho estudos sobre a pesquisa (auto)biográfica na formação de professores e aportes da Psicologia Analítica de Carl G. Jung.

\section{Afinando diálogos, delineando questôes}

Nosso primeiro movimento investigativo foi pensar sobre quais poderiam ser os elos entre a criação de narrativas cênicas, a partir da reconstrução de memórias de professores em formação, e os elementos teórico-metodológicos da pesquisa (auto)biográfica. ${ }^{1}$ Encontramos no trabalho de Josso (2004, p. 263-264) uma forma de refletir sobre tais elos:

As narrativas de histórias de vida usam uma linguagem racional e, na maioria das vezes, convencional, mas a interpretação narrativa e espontânea do itinerário de vida comporta uma dimensão imaginária, porque se trata de uma releitura do passado.

A partir dessa conceituação, passamos a indagar sobre a possibilidade de um alargamento da dimensão imaginária das narrativas de histórias de vida com base nos componentes simbólicos e imaginativos da linguagem teatral. Indagamos se, além da interpretação, também a forma de rememorar e de construir as narrativas poderia ser imaginativa e predominantemente simbólica. Tais indagaçôes nos levaram a duas questões: $\mathrm{O}$ que esse alargamento implicaria? Como olhar para os símbolos trazidos pelas narrativas cênicas?

Para refletir sobre essas questões, buscamos o referencial da Psicologia Analítica, criada por Jung, principalmente no que se refere aos processos de elaboração simbólica. Para este autor: 
(...) uma palavra ou uma imagem é simbólica quando implica alguma coisa além do seu significado manifesto e imediato. Esta palavra ou esta imagem têm um aspecto "inconsciente" mais amplo, que nunca é precisamente definido ou de todo explicado. E nem podemos ter esperanças de defini-la ou explicá-la. Quando a mente explora um símbolo, é conduzida a ideias que estão fora do alcance da nossa razão. (2002, p. 20-21)

Passamos, então, a olhar para essa prática de formação como uma possibilidade das alunas, ao produzirem e explorarem símbolos por meio das atividades expressivas, entrarem em contato com conteúdos que se encontram ainda abaixo do limiar da consciência (Jung, 2002). Tais conteúdos, que podem vir a ultrapassar esse limiar, podem atuar na consciência dessas alunas e possibilitar uma ampliação de seus pensamentos e sentimentos diante da vida e do conhecimento.

Antes de descrever como essas questóes e conceitos foram conduzindo a seleção e a análise dos dados, faz-se necessário um esclarecimento - trata-se de como o trabalho investigativo pode nos surpreender. $\mathrm{Na}$ busca por estabelecer relações entre teatro, memória e formação docente, encontramos, na única atividade plástica realizada em aula, algo que direcionou toda a reflexão realizada. Assim, levadas pela surpresa, e sem abandonar o planejado, acolhemos o revelado, entregando-nos ao "lado fascinante da pesquisa: vai-se em busca de uma pista e outras revelam-se inesperadamente ao longo do caminho" (Albano, 1998, p. 89).

No primeiro dia da prática de formação, as alunas realizaram uma dinâmica, verbalizando o que desejavam e o que não desejavam que acontecesse durante as aulas. Junto à expressão dos desejos, um barbante era jogado de mão em mão, formando uma grande teia, e durante a verbalização dos não desejos o barbante era recolhido e novamente enrolado.

Esse movimento de expandir o desejável e recolher o não desejável foi a forma escolhida para acolher as expectativas das alunas, algumas bastante temerosas em realizar atividades expressivas. Entretanto, como o indesejável também compunha suas expectativas e por isso não poderia ser desconsiderado, foi pedido para que criassem uma forma plástica em que um pedaço do barbante estivesse presente, integrando, de forma simbólica, tudo o que havia sido falado. A criação dessa forma se 
deu em grupos, os quais foram organizados pelas alunas sem qualquer intervenção externa.

Em contato com as fotos realizadas durante a última parte da dinâmica, a produção de um dos grupos chamou-nos a atenção por sua forma circular e também pelo fato do barbante ter sido utilizado como uma moldura, colorida por todas as participantes, ao mesmo tempo.

Vimos o círculo como um símbolo organizador e a união das alunas, ao concretizá-lo, como uma necessidade de organização interna. O círculo conduziu a investigação. Passamos a procurar por indícios que nos auxiliassem a refletir sobre possíveis relações entre a criação daquela imagem circular e o processo vivido por suas autoras durante a prática de formação.

Para tanto, foram selecionados os seus cadernos de campo, produzidos com o propósito de se constituírem em um instrumento de reflexão sobre a experiência vivenciada na prática formativa. Cadernos feitos de palavras e de imagens, assim como foi combinado no início do trabalho.

Em um dos cadernos estava uma réplica da produção feita no primeiro dia de aula: a folha foi preenchida por fitas coloridas e, junto ao círculo, as palavras: "eu desejo". Em outro, sua autora iniciou e finalizou-o desenhando a imagem produzida em grupo. Na primeira página, o círculo aparece junto a muitos outros fios, fazendo alusão à teia formada durante a dinâmica, e, na última, aparece junto às palavras: "e o futuro é uma astronave que devemos pilotar, e o fim dela ninguém sabe bem ao certo onde vai dar. Sem pedir licença muda a nossa vida e depois convida a rir ou chorar". 2

A partir desses dados, passamos a indagar se a necessidade de organização interna não estaria relacionada ao fato dessas alunas estarem cursando o último semestre do curso, de estarem vivendo um momento de transição, sendo a transição de aluna para professora, talvez, a mais difícil delas.

Nos cadernos de outras duas meninas do grupo, a necessidade de se fortalecerem para a transição e a despedida se faz presente. Neles há indícios de como o processo com a linguagem do teatro e com as memórias as ajudou a vivenciar essa transição. 
Mais uma vez, a primeira página se revela repleta de significados, construídos por imagens e palavras: "O Começo do Fim", escrito em vermelho dentro de um palco semifechado por cortinas vermelhas.

O texto-imagem, criado por essa aluna, traz indícios de que a experiência com o teatro, vivida na prática de formação, pode ter sido um lugar em que sentimentos sobre o seu momento de transição foram frequentes, ganhando maior vazão, espaço, possibilidades.

O outro caderno também traz as cortinas do teatro: "Cortinas vermelhas sendo fechadas.... É o fim de mais um espetáculo!!!! Mais uma fase da minha vida, outra página virada! Que venham novas cenas, novos personagens, novos cenários, novos figurinos, novos diretores, novos atores... Enfim... NOVOS SENTIMENTOs!!!!!!” (grifo da autora).

A partir dessa análise dos dados selecionados, passamos a identificar os cadernos de campo, feitos de palavras e imagens, também como uma possibilidade das alunas se aproximarem de seus processos e necessidades internas, produzindo e explorando símbolos.

Concluímos essa pequena incursão realizada pela prática de formação, identificando os processos de criação, vivenciados pelas alunas, como espaços privilegiados para a produção e elaboração de símbolos, potencializando a ordenação do vivido por meio do rememorar, do encenar histórias de vida e do registro das experiências de formação com palavras, imagens, formas e cores. Prática, ainda, pouco considerada na formação de professores e que pode possibilitar "outros modos de conhecer, qualificando sensibilidade, sentimento e intuição" (Ostetto, 2006, p. 232). Modos de conhecer que possam se unir aos já existentes, agindo na integração das polaridades pensamento e sentimento.

\section{Notas}

1. Sobre essa abordagem, ver Bueno (2002), Catani et al. (1997), Josso (2004), Nóvoa (1995), Passeggi e Barbosa (2008), Souza (2006).

2. Note-se que tais palavras reproduzem trecho da letra da conhecida música Aquarela, composta por Toquinho, Vinicius de Moraes, G. Morra e M. Fabrizio.

\section{Referências}

ALBANO, A.A. Tuneu, Tarsila e outros mestres: o aprendizado da arte como rito de iniciação. São Paulo: Plexus, 1998. 189p. 
BUENO, B.O. O método autobiográfico e os estudos com histórias de vida de professores. Educação \& Pesquisa, São Paulo, v. 28, n. 1, p. 11-30, jan./jun. 2002.

CATANI, D.B. et al. (Org.). Docência, memória e gênero: estudos de formação. São Paulo: Escrituras, 1997.

JOSSO, M.-C. Experiências de vida e de formação. São Paulo: Cortez, 2004. 285p.

JUNG, C.G. Chegando ao inconsciente. In: JunG, C.G. (Org). O homem e os seus símbolos. 22. ed. Rio de Janeiro: Nova Fronteira, 2002. p. 18-103.

NÓVOA, A. Os professores e as histórias da sua vida. In: NóvoA, A. (Org.). Vidas de professores. 2. ed. Porto: Porto, 1995. p. 11-30.

OSTETTO, L.E. Educadores na roda da dança: formação-transformação. 2006. 250f. Tese (Doutorado em Educação) - Programa de PósGraduação em Educação, Universidade Estadual de Campinas, Campinas.

PASSEGGI, M.C.; BARBOSA, T. (Org.). Narrativas de formação e saberes biográficos. Natal: EDUfRn; São Paulo: Paulus, 2008. 274p.

SOUZA, E.C. O conhecimento de si: estágio e narrativas de formação de professores. Rio de Janeiro: DP\&A; Salvador: UNEB, 2006. 184p. 